${ }^{[0000-0002-8342-3011]}$ О. О. Онищук, к.т.н., доцент e-mail: oksanaduda2013@gmail.com

Волинський національний університет імені Лесі Українки Потапова, 9, м. Луцьк, 43000, Україна

\title{
ОПТИМІЗАЦІЯ РОЗРАХУНКУ ТЕМПЕРАТУРИ ТА ШВИДКОСТІ ДЛЯ ТЕПЛООБМІННИХ ПРОЦЕСІВ В АДІАБАТИЧНИХ УМОВАХ
}

У статті показано модель теплообміну для ииліндричної заготовки з нестаціонарним режимом в адіабатичних умовах. Визначено середню швидкість поширення тривимірного фронту теплообміну вздовж ичиліндра та середню поперечну температуру для ивого режиму через рівняння теплопровідності та рівняння кінетики. Крім того, визначено вплив радіуса циліндра на швидкість теплообміну. Використовуючи рівняння теплопровідності та граничні умови, визначено середню поперечну температуру ичліндра при теплообміні. Також використовуючи рівняння кінетики, отримуємо значення середньої швидкості поширення тривимірного фронту вздовж ичліндра для нестачіонарного режиму в адіабатичних умовах. Досліджено через параметр $R_{0}$, який показує, наскільки радіус ииліндра більший характеристичної величини зони реакиї, що при збільшенні радіуса швидкість теплообміну незначно зменшується. Графічно показано залежність $R_{0}$ від характеристичної величини зони реакиії $G / T d$ для двох режимів ступеня віддалення від області. Використовуючи рівняння теплопровідності та рівняння кінетики з початковими і граничними умовами, визначено середню швидкість поширення фронту вздовж ииліндра для нестаціонарного режиму в адіабатичних умовах та середню поперечну температуру. Розв'язано осесиметричну граничну задачу нестаціонарного теплообміну з рухом фронту тепла уздовж осі симетрії ичиліндра. Приведена математична модель теплообмінного процесу досліджувалася із застосуванням методу кінцевих різниць і програмного забезпечення ANSYS. Показано, що температура глибини перетворення теплообміну знаходиться в перерізі, перпендикулярному осі ииліндра, який проходить через точку з максимальною температурою, причому, чим вища температура, тим світліша штриховка області.

Ключові слова: теплообмін, ииліндрична заготовка, математична модель, температуpa, теплові процеси, метод кінцевих різниць, ANSYS.

Вступ. Теплообмінні процеси як хімікотехнологічний прийом дають можливість одержувати цільові продукти при великій продуктивності процесу i низькій вартості витрат на його організацію $[1,2]$. В теплових процесах беруть участь не менш як два середовища 3 різними температурами. Середовище $з$ більш високою температурою, яке віддає при теплообміні тепло, називається теплоносієм, середовище з більш низькою температурою - холодильним агентом (холодоагентом). Теплообмін має важливе значення для проведення процесів випаровування, сушіння, перегонки й ін. С три способи передачі теплоти: теплопровідність, конвекція і випромінювання. Теплопровідність - явище перенесення теплової енергії безпосереднім контактом між частинками тіла $[3,9]$.

Математичне моделювання теплообмінних процесів, що базується на їх математичному описі, досить давно використовуєть(C) О. О. Онищук, 2021 DOI: $10.24025 / 2306-4412.1 .2021 .222804$ ся в техніці $[8,9,11,12]$. Проте зміст математичного моделювання, його можливості та актуальність створення математичних моделей зазнали докорінних змін. Це пов'язано 3 перевагами цих методів перед натуральним експериментом, зі швидким розвитком засобів обчислювальної техніки та їі математичного забезпечення і з удосконаленням наявних та розробкою нових чисельних методів реалізації складних математичних моделей, що використовують математичний апарат диференціального й інтегрального числення [9]. Сучасні математичні моделі дають змогу одержати розрахунковим шляхом велику і досить точну інформацію про різні теплові процеси в техніці. Проведення обчислювальних експериментів з математичною моделлю, що реалізована у вигляді комп'ютерної програми, забезпечує скорочення термінів дослідження і зменшення його вартості, дає можливість прогнозувати поведінку досліджуваного об'єкта в різних, 
у тому числі й екстремальних ситуаціях, створюючи, таким чином, основу для теплотехнічного обгрунтування проектних рішень при розробці нових і вдосконаленні наявних технологічних процесів з метою зниження енергоємності виробництва і підвищення якості продукції [10-15].

Мета та постановка задачі. Оскільки на теплообмін впливає одночасно декілька факторів: швидкість, напрямок, розміри моделі, початкова температура, температура середовища та умови, в яких відбувається безпосередньо сам процес, тому важливо дослідити ці фактори.

Виклад основного матеріалу. Поширення тепла починалося локально у точці. Надалі процес проходить у режимі пошарового поетапного руху. У відомих роботах 3 вивчення теплового режиму теплообмінних процесів розглядалася подібна осесиметрична задача нестаціонарного теплообміну 3 рухом уздовж осі симетрії циліндричної системи на початковому етапі $[6,11]$.

Оскільки після початку поширення тепла відбувається ініціювання реакції, теплообмін здійснюється і на бічній поверхні, і фронт тепла рухається перпендикулярно до осі симетрії.

Параметри теплового режиму і розмірність розв'язуваної задачі залежать від координат початкової точки теплообмінного процесу. Оскільки в нашому випадку можливий початок руху тепла 3 центру торця або ж 3 бічної поверхні циліндра, то протягом усього часу теплообміну реалізується осесиметричний теплообмін.

У ролі основного об'єкта дослідження розглядається теплообмінний процес у циліндрі. Таким чином, осесиметричним має бути і температурне поле циліндра.

Розглядаємо двовимірну модель теплообміну при теплообміні плоского шару одиничної товщини циліндра. Шар вирізається таким чином, щоб його довжина дорівнювала максимально можливому шляху теплообміну. Відповідно площини перерізу проходять чеpeз початкову точку поширення i найбільш віддалену від неї точку.

Така модель дає змогу описати поле температур у найбільш холодній (початок теплообміну) і гарячій (закінчення теплообміну) зонах циліндра (рисунок 1).
3 математичної точки зору, процес теплообміну описується системою рівнянь теплоі масопереносу з джерелами тепла і продуктів, обумовленого хімічною реакцією [6, 7]. Наявність членів, експоненціально залежних від температури, визначає всі специфічні риси, властиві теплообмінним процесам.

Рішення цієї системи рівнянь виражає просторово-часовий розподіл температур, концентрації реагентів і продуктів, швидкостей реакції та інших показників процесу $[8,9,11]$.

Реакція теплообміну проходить одночасно в усьому об'ємі тіла. Тепло, що виділяється, частково відводиться в навколишнє середовище, а частково залишається в системі і підвищує iї температуру. Температура змінюється від початкового значення до деякої величини, що відповідає повному адіабатичному перетворенню реагентів.

Ця модель дає можливість описати механізм руху теплообміну для нестаціонарного режиму горіння в адіабатичних умовах та визначити середню швидкість поширення теплообміну в спіновому режимі. Крім того, використовуючи основні кінетичні рівняння теплообміну, визначимо вплив радіуса на швидкість горіння (рисунок 1).

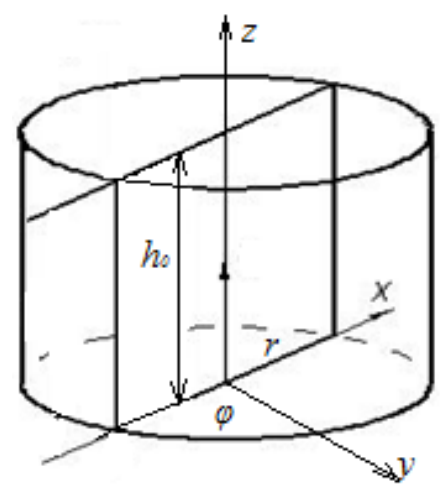

Рисунок 1 - Схематична модель руху теплообміну в циліндричній заготовці

Результати досліджень. В безрозмірному вигляді математична модель руху теплообміну включає рівняння теплопровідності [12-14]

$$
\frac{\partial \theta}{\partial \tau}=\frac{\partial^{2} \theta}{\partial x^{2}}+\frac{1}{x} \frac{\partial \theta}{\partial x}+\frac{1}{x^{2}} \frac{\partial^{2} \theta}{\partial \varphi^{2}}+\frac{\partial^{2} \theta}{\partial z^{2}}+\frac{1}{T d} \frac{\partial \eta}{\partial \tau}
$$

і рівняння кінетики $[11,13]$

$$
\frac{\partial \eta}{\partial \tau}=\left\{\begin{array}{c}
T d(1-\eta) \exp \frac{\theta}{1+\operatorname{Ar} \theta} \text { nри } \eta<1, \\
0 \text { при } \eta \geq 1
\end{array}\right.
$$


Система рівнянь має початкові і граничні умови [10]:

$$
\begin{gathered}
\tau=0,0 \leq x \leq R_{0}, 0 \leq \varphi \leq 2 \pi, 0 \leq z \leq z_{0}: \theta=\theta_{0}, \eta=0 ; \\
\tau>0, x=R_{0}, 0 \leq \varphi \leq 2 \pi, 0 \leq z \leq z_{0}: \frac{\partial \theta}{\partial x}=-\alpha_{T}\left(\theta-\theta_{0}\right) ; \\
\tau>0,0 \leq x \leq R_{0}, 0 \leq \varphi \leq 2 \pi, z=0: \frac{\partial \theta}{\partial z}=0 ; \\
\tau>0,0 \leq x \leq R_{0}, 0 \leq \varphi \leq 2 \pi, z=z_{0}:\left\{\begin{array}{l}
\theta=0 n p u \tau \leq \tau_{i g n} \\
\frac{\partial \theta}{\partial z}=0 n p u \tau<\tau_{i g n} .
\end{array}\right. \\
\theta=\frac{\left(T-T_{*}\right) E}{R T_{*}^{2}}, t_{*}=\frac{c R T_{*}^{2}}{k_{0} E Q} \exp \frac{E}{R T_{*}}, \tau=\frac{t}{t_{*}}, \tau_{i g n}=\frac{t_{i g n}}{t_{*}} . \\
h_{*}^{2}=\frac{\lambda t^{*}}{c \rho_{0}}, x=\frac{r}{h *}, z=\frac{h}{h *}, R_{0}=\frac{r_{0}}{h *}, z_{0}=\frac{h_{0}}{h *}, A r=\frac{R T *}{E} ; \\
T d=\frac{c R T_{*}^{2}}{E Q}, \theta_{0}=-\frac{1}{T d}, \alpha_{T}=\frac{\alpha_{t} h *}{\lambda}, \mathrm{T}_{*}=\mathrm{T}_{0}+\mathrm{Q} / \mathrm{c},
\end{gathered}
$$

де $T$ - температура, $T_{*}$ - характеристична температура, яку приймають за адіабатичну температуру теплообміну, $T_{0}$ - температура навколишнього середовища і початкова температура зразка, $C$ - питома теплоємкість, $Q-$ тепловий ефект реакції, $\eta$ - глибина перетворення, $\rho_{0}$ - маса конденсованої фази в одиниці об'єму, $t$ - час, $r, \varphi, h$ - просторові координати: радіус, кут і координата вздовж осі циліндра відповідно, $\lambda$ - теплопровідність, $K_{0}-$ пе- редекспотенціальний множник, $E$ - енергія активації, $R$ - універсальна стала, $\alpha_{T}$ - коефіцієнт тепловіддачі від поверхні зразка в навколишнє середовище, $r_{0}, h_{0}$ - радіус і висота циліндра, $t_{i g n}$ - час дії запалюючого імпульсу, $T_{d}-$ критерії Тодеса, $A_{r}-$ критерій Арреніуса. Математична модель теплообміну [11]:

1) систему трьох диференціальних рівнянь нестаціонарної теплопровідності в декартових координатах:

$$
C_{i} \rho_{i} \frac{\partial T_{i}(x, y, t)}{\partial t}=\frac{\partial}{\partial x}\left(\lambda_{i} \frac{\partial T_{i}(x, y, t)}{\partial x}\right)+\frac{\partial}{\partial y}\left(\lambda_{i} \frac{\partial T_{i}(x, y, t)}{\partial y}\right) ;
$$

2) граничні умови:

на границі фаз ( $\left.x=0, y=h_{1}\right)$ умови I роду

$$
\left.\begin{array}{c}
\lambda_{1} \frac{\partial T_{1}(0, y, t)}{\partial x}=\lambda_{2} \frac{\partial T_{2}(0, y, t)}{\partial x} ; T_{1}(0, y, t)=T_{2}(0, y, t) ; \\
\lambda_{1} \frac{\partial T_{1}\left(x, h_{1}, t\right)}{\partial y}=\lambda_{2} \frac{\partial T_{2}\left(x, h_{1}, t\right)}{\partial y} ; T_{1}\left(x, h_{1}, t\right)=T_{2}\left(x, h_{1}, t\right) ;
\end{array}\right\} ;
$$

3) початкові умови:

$$
T_{1}\left(0, y_{1}, 0\right)=T_{\text {г }} ; T_{2}(x, y, 0)=T_{0} ;
$$

4) рівняння руху фронту тепла:

$$
x_{\mathrm{\Gamma}}=s_{\mathrm{\Gamma}} \cdot t \text {; }
$$

5) температура рухомої границі I роду (фронт горіння) при $h_{1}=y_{1}$ :

$$
T\left(x_{\mathrm{\Gamma}}, y_{1}, t\right)=T_{\mathrm{\Gamma}} \text {; }
$$

6) умови симетрії температурного поля відносно осі $x$ :

$$
\frac{\partial T_{1}(x, 0, t)}{\partial y}=0
$$

7) умови адіабатичності перед фронтом тепла $\left(x=x_{\Gamma}+0\right)$ :

$$
\frac{\partial T_{1}\left(x_{\Gamma}+0, y_{1}, t\right)}{\partial x}=0 .
$$

При розрахунку температурного поля процесу теплообміну всього шару системи рівнянь (1)-(11) виключаються рівняння (8)- 
(9) і додаються граничні умови першого роду на торцевій поверхні шару при $x=1$ :

$$
\begin{gathered}
\frac{\partial T(x, t)}{\partial t}=\alpha_{0} \frac{\partial^{2} T(x, t)}{\partial t} \\
T_{1}(h, y, t)=T_{2}(h, y, t) .
\end{gathered}
$$

У (6)-(10) позначено: $T_{i}$ - температура процесу теплообміну, $T_{1}, T_{2}$ - температура на початку процесу та в кінці відповідно; $C_{i}, \rho_{i}, \lambda_{i}-$ питома теплоємність, густина і коефіцієнт теплопровідності; $h_{i}$ - характерні розміри зразка; $i$ - індекс системи: $t$ - час; $x_{\text {г }}$ - текуча координата процесу теплообміну; $\alpha_{\text {т }}$ - коефіцієнт тепловіддачі; $T_{2}, T_{0}$ - температура тіла та середовища відповідно; $s_{\Gamma}-$ швидкість теплообміну.

Визначаємо початкову температуру через прогнозування основної температури, яка базується на основі моделі напівбезмежного тіла. Використовуємо замість рівняння теплопровідності (1) спрощене одновимірне рівняння теплопровідності

$$
\frac{\partial T(x, t)}{\partial t}=\alpha_{0} \frac{\partial^{2} T(x, t)}{\partial t}
$$

де $\alpha_{0}-$ коефіцієнт тепловіддачі.

Інтенсивність теплового потоку або питомий тепловий потік $q$ (густина теплового потоку) - це потужність теплової іскри, поділена на площу поверхні фронту зразка, тобто кількість теплоти, яка проходить $1 \mathrm{~m}^{2}$ площі поверхні за одиницю часу.

Використовуючи початковий час ініціювання та початкову температуру, розраховують тепловий потік.

Тепловий потік пропорційний градієнту температури (закон Фур'є) [11]:

$$
q=-\lambda \frac{\partial T(x, t)}{\partial x}
$$

Початкові умови:

$$
0<x<\infty, t>0, T(x, 0)=T_{i} .
$$

Крайові умови:

$$
-\lambda \frac{\partial T(x, t)}{\partial x}=\left.\alpha_{0} \frac{\partial^{2} T(x, t)}{\partial x}\right|_{x=0}=q_{0}
$$

Скористаємося перетворенням Лапласа. Трансформанту позначаємо тильдою « $\widetilde{T} »$ :

$$
\frac{\partial T}{\partial t} \rightarrow \tilde{T}(x, s)-T(x, 0),
$$

оскільки

$$
\begin{aligned}
T(x, 0)=T_{i}, \text { то } & \\
\frac{\partial T}{\partial t} & \rightarrow \tilde{T}(x, s)-T_{i},
\end{aligned}
$$

тоді

$$
\frac{\partial^{2} T}{\partial x} \rightarrow \frac{\partial^{2} \tilde{T}(x, s)}{\partial x^{2}}
$$

де $x$ - текуча координата фронту горіння; $\alpha_{T}$ - коефіцієнт тепловіддачі, $s$ - швидкість поширення фронту горіння, $T_{i}$ - температура ініціювання.

Таким чином, отримуємо

$T(x, t) \rightarrow$ рівняння в трансформантах:

$$
\frac{\partial^{2} T(x, s)}{\partial x}-\frac{s \widetilde{T}(x, s)}{\alpha_{0}}=\frac{T_{i}}{\alpha_{0}}
$$

Характеристичне рівняння:

$$
x^{2}-\frac{s}{\alpha_{0}}=0, x= \pm \sqrt{\frac{s}{\alpha_{0}}}
$$

Частинний розв'язок:

$$
-\frac{s}{\alpha_{0}} A=-\frac{T_{i}}{\alpha_{0}} \rightarrow A=\frac{T_{i}}{S}, T_{\Gamma}=\frac{T_{i}}{S}
$$

Повний розв'язок:

$$
\mathrm{T}=\mathrm{C}_{1} e^{-\sqrt{\frac{S}{\alpha_{0}}}}+\mathrm{C}_{2} e^{-\sqrt{\frac{S}{\alpha_{0}}}}+\frac{T_{i}}{S}
$$

3 умови обмеженості $\tilde{T}$ при $x \rightarrow \infty$ випливає, що $C_{2}=0$. Крайова умова в трансформантах має вигляд:

$$
\begin{gathered}
\left.\frac{\partial^{2} T(x, t)}{\partial x}\right|_{x=0}=-\frac{q_{0}}{\lambda \cdot S} \\
\left.\frac{\partial \tilde{T}}{\partial x}\right|_{x=0}=-\left.\left(\widetilde{N_{1}} e^{-\sqrt{\frac{S}{\alpha_{0}} x}}\right)\right|_{x=0}=-C_{1} \sqrt{\frac{S}{2}} \rightarrow \\
C_{1}=\frac{q_{0 \sqrt{\alpha}}}{\lambda \cdot S^{\frac{3}{2}}} \\
Q=\frac{q_{0 \sqrt{\alpha}}}{\lambda \cdot S^{3 / 2}} e^{-\sqrt{\frac{S}{\alpha_{0}} x}}+\frac{T_{i}}{S}
\end{gathered}
$$

Отже, початкова температура:

$$
\begin{gathered}
\mathrm{T}(x, t)=T_{i}+\frac{q_{0}}{\lambda \sqrt{\pi}}\left(-\sqrt{\pi} x^{e 2 \lambda \frac{x}{2 \sqrt{\alpha_{0} t}}}\right)+ \\
2 \sqrt{\alpha_{0} t e^{\frac{x^{2}}{-4}} \alpha_{0} t}
\end{gathered}
$$

Вважаючи сталою інтенсивність теплового потоку $q_{0}{ }_{0}$ та припускаючи, що початкова температура $T_{i}$ - стала $\left(T_{i}=\mathrm{const}\right)$, розподіл температури можна виразити так:

$$
\begin{aligned}
& \mathrm{T}(x, t)-T_{i}=\frac{\frac{2 q^{\prime \prime}{ }_{0}\left(\alpha_{0} t\right)}{\pi}}{\lambda} \exp \left(\frac{-x^{2}}{4 \alpha_{0} t}\right)- \\
& \frac{q^{\prime \prime}{ }_{0} x}{\lambda} \operatorname{erfc}\left(\frac{x}{2 \sqrt{\alpha_{0} t}}\right)
\end{aligned}
$$

Таким чином, розглянуто осесиметричну граничну задачу нестаціонарного теплообміну двовимірної моделі на стадії синтезу з рухом теплообміну уздовж осі симетрії циліндричного зразка. 
Обговорення результатів. Приведена математична модель процесу досліджувалась чисельно із застосуванням методу кінцевих різниць та програмного забезпечення ANSYS $[14,15]$

Таким чином, на рисунку 2 зображено тривимірну модель теплообміну у циліндрі в нестаціонарному режимі [5].

Використовуючи розрахункову просторову сітку, яка $\epsilon$ нерівномірною, з нефіксованою кількістю вузлів, забезпечувалось згущення вузлів сітки в області фронту і у міру зміні температури зразка відбувалось нарощування зразка з боку реагентів і відсікання віддаленої від фронту частини продуктів. Сітка використана через наскрізний перетин по діаметру.

Температура глибини перетворення теплообміну знаходиться в перерізі, перпендикулярному осі циліндра, який проходить через точку 3 максимальною температурою, причому, чим вища температура, тим світліша штриховка області.

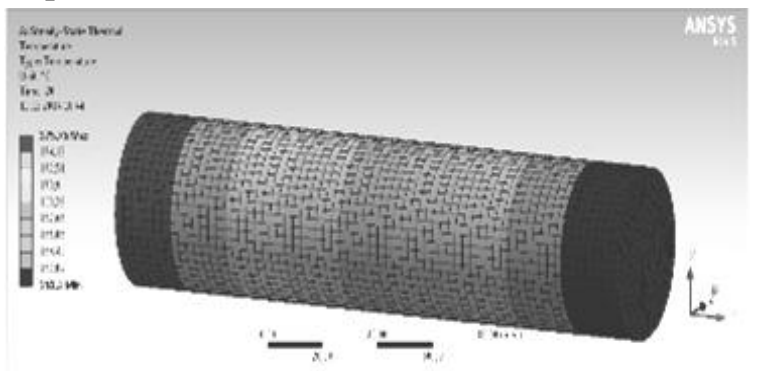

Рисунок 2 - Теплообмінний режим для циліндричної заготовки 3 нестаціонарним режимом в адіабатичних умовах

$A_{\mathrm{r}}=0,0529, T_{d}=0,1087, a_{s t} \approx 0,86 R_{0} \approx 58$

Використовуючи рівняння теплопровідності (1), а також граничні умови (3), визначаємо середню поперечну температуру циліндра при теплообміні:

$$
\bar{\theta}(z, t)=\frac{1}{\pi R_{0}^{2}} \int_{0}^{R_{0}} \int_{0}^{2 \pi} \theta(x, \varphi, z, t) d \varphi d r .
$$

Використовуючи рівняння теплопровідності (1) та рівняння кінетики (2), отримуємо значення середньої швидкості поширення тривимірного фронту вздовж циліндра для нестаціонарного режиму в адіабатичних умовах $\bar{u}=\frac{1}{\pi R_{0}^{2}\left(\tau_{k}-\tau_{0}\right)} \iiint_{V} \eta\left(x, \varphi, z, \tau_{k}\right) d V-\iiint_{V} \eta\left(x, \varphi, z, \tau_{0}\right) d V$,

де $\tau_{k}, \tau_{0}$ - час початку і кінця процесу на певному періоді розрахунку, $V$ - об'єм циліндра.
Як параметри використовували $\alpha_{s t}$ i $R_{0}$. Параметр $\alpha_{s t}$, визначений у роботі, характеризує ступінь віддалення від області, в якій плоский стаціонарний фронт є нестійким.

$$
\alpha_{s t}=9,1 T_{d}-2,5 A r<1 .
$$

Границя, що розділяє стійкі і нестійкі одномірні режими, визначається умовою $\alpha_{s t}=1$.

Параметр $R_{0}$ показує, наскільки радіус циліндра більший характеристичної величини зони реакції.

На рисунку 3 зображено залежність $R_{0}$ від характеристичної величини зони реакції $G / T d$ для двох режимів ступеня віддалення від області $\alpha_{s t}$, де видно, що ступінь віддалення від області $\alpha_{s t}=1$ більший при більших значеннях $R_{0}$.



\section{Рисунок 3 - Залежність радіуса $\boldsymbol{R}_{\mathbf{0}}$ від характеристичної величини зони реакції $G / T d$}

Висновки. Таким чином, описано механізм теплообмінного руху для нестаціонарного режиму в адіабатичних умовах.

Використовуючи рівняння теплопровідності та рівняння кінетики 3 початковими і граничними умовами, визначено середню швидкість поширення фронту вздовж циліндра для нестаціонарного режиму в адіабатичних умовах та середню поперечну температуру.

Розв'язано осесиметричну граничну задачу нестаціонарного теплообміну 3 рухом фронту тепла уздовж осі симетрії циліндра.

Досліджено, що при більшому радіусі швидкість теплообміну незначно зменшується.

Отже, використання процесу їх теплообміну у хімічній технології приводить до висновку про те, що нині вони мають значні перспективи. 


\section{Список використаних джерел}

[1] Я. Б. Зельдович, и Д. А. Франк-Каменецкий, "Теория теплового распространения пламени", Журнал физической химии, т. 12, № 1, с. 100-105, 1938.

[2] Д. А. Франк-Каменецкий, "Распределение температур в реакционном сосуде и стационарная теория теплового взрыва", Журнал физической химии, т. 13, № 6, c. $738-755,1939$.

[3] А. Г. Касаткин, Основные проиессы и аппараты химической технологии. Москва, Россия: Химия, 1974.

[4] А. Н. Плановский, и П. И. Николаев, Проиессы и аппарать химической $u$ нефтехимической технологии. Москва, Россия: Химия, 1972.

[5] А. П. Врагов, Гідромеханічні прочеси та обладнання хімічних $і$ нафтохімічних виробництв: навч. посіб. Суми: Вид-во Сум. держ. ун-ту, 2001.

[6] В.Н. Стабников, В.М.Лысянский, и В. Д. Попов, Прочессы и апnараты пищевых производств. Москва, Россия: Агропромиздат, 1985.

[7] Н.И. Гельперин, Основные прочессы и аппараты химической технологии. Москва, Россия: Химия, 1981.

[8] В. М. Чесунов, и А. А. Захарова, Основные химико-технологические процессы и аппараты в производстве легкой промылиленности: учебник для вузов. Москва, Россия: Легпромбытиздат, 1989.

[9] О. Флореа, и О. Смигельский, Расчеты по проиессам и аппаратам химической технологии: пер. с рум. / под ред. С. З. Кагана. Москва, Россия: Химия, 1971.

[10] В. С. Бодров, А. Т. Богориш, П. Т. Лобода, и В. М. Лысянский, Проектирование процессов и аппаратов пищевых производств / под ред. В. Н. Стабникова. Киев, Украина: Вища школа, 1982.

[11] Основные процессы и аппараты химической технологии: пособие по проектированию / под ред. Ю. И. Дытнерского. Москва, Россия: Химия, 1983.

[12] Расчеты химико-технологических процессов / под общ. ред. И. П. Мухленова. Ленинград, Россия: Химия, 1976.

[13] В. М. Лекае, и А. К. Лекае, Процессы и аппараты химической промышленности. Москва, Россия: Высшая школа, 1984.
[14] Справочник химика. Ленинград, Россия: Химия, 1968. T. IV.

[15] В. А. Бруяка, В. Г. Фокин, Е. А. Солдусова, Н. А. Глазунова, и И. Е. Адеянов, Инженерный анализ в ANSYS Workbench: учеб. пособ. Самара: Самар. гос. техн. ун-т, 2010.

\section{References}

[1] Ya. B. Zel'dovich, and D. A. Frank-Kamenetskiy, "Theory of thermal propagation of flame", Zhurnal fizicheskoy khimii, vol. 12, no. 1, pp. 100-105, 1938 [in Russian].

[2] D. A. Frank-Kamenetskiy, "Temperature distribution in a reaction vessel and the stationary theory of thermal explosion", Zhurnal fizicheskoy khimii, vol. 13, no. 6, pp. 738-755, 1939 [in Russian].

[3] A. G. Kasatkin, Basic processes and devices of chemical technology. Moscow, Russia: Khimiya, 1974. [in Russian].

[4] A. N. Planovsky, and P. I. Nikolaev, Processes and devices of chemical and petrochemical technology. Moscow, Russia: Khimiya, 1972. [in Russian].

[5] A. P. Vragov, Hydromechanical processes and equipment of chemical and petrochemical productions: textbook. Sumy: Vydvo Sum. derzh. un-tu, 2001 [in Ukrainian].

[6] V. N. Stabnikov, V. M. Lysyansky, and V. D. Popov, Processes and apparatus for food production. Moscow, Russia: Agropromizdat,1985 [in Russian].

[7] N. I. Gelperin, Basic processes and devices of chemical technology. Moscow, Russia: Khimiya, 1981 [in Russian].

[8] V. M. Chesunov, and A. A. Zakharova, The main chemico-technological processes and devices in the production of light industry: manual for universities. Moscow, Russia: Legprombytizdat, 1989 [in Russian].

[9] O. Florea, and O. Smigelsky, Calculations on processes and apparatuses of chemical technology: transl. from Rom., S. Z. Kagan, Ed. Moscow, Russia: Khimiya, 1971 [in Russian].

[10] V. S. Bodrov, A. T. Bogorish, P. T. Loboda, and V. M. Lysyansky, Design of processes and apparatus for food production, V. N. Stabnikov, Ed. Kiev, Ukraine: Vishcha shkola. 1982 [in Russian].

[11] Basic processes and devices of chemical technology: design manual, Yu. I. Dyt- 
nersky, Ed. Moscow, Russia: Khimiya, 1983 [in Russian].

[12] Calculations of chemical-technological processes, I. P. Mukhlenov, Ed. Leningrad, Russia: Khimiya, 1976 [in Russian].

[13] V. M. Lekae, and A. K. Lekae, Processes and apparatus of chemical industry. Moscow, Russia: Vysshaya shkola, 1984 [in Russian].
[14] Handbook of a chemist. Leningrad, Russia: Khimiya, 1968, vol. IV [in Russian].

[15] V. A. Bruyaka, V. G. Fokin, E. A. Soldusova, N. A. Glazunova, and I. E. Adeyanov, Engineering analysis in ANSYS Workbench: textbook. Samara: Samar. gos. techn. un-t, 2010 [in Russian].

O. O. Onyschuk, Ph.D., associate professor e-mail: oksanaduda2013@gmail.com

Lesya Ukrainka Volyn National University Potapova, 9, Lutsk, 43000, Ukraine

\section{OPTIMIZATION OF TEMPERATURE AND SPEED CALCULATION FOR HEAT EXCHANGE PROCESSES IN ADIABATIC CONDITIONS}

The article shows a model of heat exchange for a cylindrical workpiece with a non-stationary regime in adiabatic conditions. The average velocity of propagation of three-dimensional heat exchange front along the cylinder and the average transverse temperature for this mode are determined through the equations of thermal conductivity and the equation of kinetics. In addition, the influence of the cylinder radius on the heat transfer rate is determined, It has been shown that the average transverse temperature of the cylinder during heat transfer is determined using the equations of thermal conductivity and boundary conditions. Also using the equation of kinetics, we obtain the value of the average velocity of propagation of the three-dimensional front along the cylinder for nonstationary mode in adiabatic conditions. It is investigated through the $R_{0}$ parameter, which shows how much the radius of the cylinder is larger than the characteristic value of the reaction zone, that with increasing the radius, the heat transfer rate decreases slightly. The dependence of $R_{0}$ on the characteristic value of the reaction zone $G / T d$ for two modes of the degree of distance from the region is graphically shown. Using the equations of thermal conductivity and the equations of kinetics with initial and boundary conditions, the average velocity of propagation of the front along the cylinder for the nonstationary regime in adiabatic conditions and the average transverse temperature are determined.

The axisymmetric boundary value problem of nonstationary heat exchange with the motion of the heat front along the axis of symmetry of the cylinder is solved. The given mathematical model of heat exchange process has been investigated using the finite difference method and ANSYS software. It is shown that the temperature of the heat transfer transformation depth is in the section, perpendicular to the axis of the cylinder, which passes through the point with the maximum temperature, and the higher the temperature, the lighter the shading of the area.

Keywords: heat transfer, cylindrical workpiece, mathematical model, temperature, thermal processes, finite difference method, ANSYS.

Стаття надійшла 10.01.2021

Прийнято 05.03.2021

(C) О. О. Онищук, 2021

DOI: $10.24025 / 2306-4412.1 .2021 .222804$ 